Illinois State University

ISU ReD: Research and eData

Theses and Dissertations

7-17-2014

\title{
The Effects Of Community Support On Posttraumatic Growth Outcomes For Parents Of Children With Chronic Illness
}

Colleen Gannon

Illinois State University, cgannon@ilstu.edu

Follow this and additional works at: https://ir.library.illinoisstate.edu/etd

Part of the Family, Life Course, and Society Commons, Psychiatric and Mental Health Commons, and the Social Psychology Commons

\section{Recommended Citation}

Gannon, Colleen, "The Effects Of Community Support On Posttraumatic Growth Outcomes For Parents Of Children With Chronic Illness" (2014). Theses and Dissertations. 242.

https://ir.library.illinoisstate.edu/etd/242

This Thesis is brought to you for free and open access by ISU ReD: Research and eData. It has been accepted for inclusion in Theses and Dissertations by an authorized administrator of ISU ReD: Research and eData. For more information, please contact ISUReD@ilstu.edu. 


\title{
THE EFFECTS OF COMMUNITY SUPPORT ON POSTTRAUMATIC GROWTH OUTCOMES FOR PARENTS OF CHILDREN WITH CHRONIC ILLNESS
}

\author{
Colleen C. Gannon
}

67 Pages

December 2014

Parents of children with chronic illnesses face many stressors on multiple fronts as a result of their child's care needs. Posttraumatic growth is positive psychological outcomes of stress for those who have experienced a traumatic event, such as the diagnosis of a child with a chronic illness. While much is known about the challenges of caring for a child with a chronic condition, there is little research on these parent's growth outcomes. Of the research that does exist, much focuses on internal predictors of posttraumatic growth, such as personality characteristics. The purpose of this study is to begin to investigate the connections between community belonging and the posttraumatic growth experiences of parents of children with chronic illnesses. This study was conducted using both quantitative analysis with the Posttraumatic Growth Inventory (PTGI; Tedeschi \& Calhoun,1996) and the Perceived Community Support Questionnaire (PCSQ; Herreo \& Garcia, 2007), which were completed by parents, and qualitative analysis which included child life specialists' observations of the role of creating community within the hospital and parents' growth experiences. While total PTGI and PCSQ scores were not significantly correlated, correlations between the Community 
Integration dimension of the PCSQ and certain factors of the PTGI suggest that greater community integration is positively related to new possibilities, personal strength, and appreciation of life. Child life specialists' responses suggested that creating community through hospital programming contributes to parents' growth experiences. 
THE EFFECTS OF COMMUNITY SUPPORT ON POSTTRAUMATIC GROWTH OUTCOMES FOR PARENTS OF CHILDREN WITH CHRONIC ILLNESS

\author{
COLLEEN C. GANNON
}

A Thesis Submitted in Partial Fulfillment of the Requirements for the Degree of

MASTER OF SCIENCE

Department of Family and Consumer Sciences

ILLINOIS STATE UNIVERSITY 
Copyright 2014 Colleen C. Gannon 
THE EFFECTS OF COMMUNITY SUPPORT ON POSTTRAUMATIC GROWTH OUTCOMES FOR PARENTS OF CHILDREN WITH CHRONIC ILLNESS

\author{
COLLEEN C. GANNON
}

COMMITTEE MEMBERS:

Bill Anderson, Chair

Hae Jin Gam

Connor Walters 


\section{ACKNOWLEDGMENTS}

I would like to thank my committee, Dr. Bill Anderson, Dr. Hae Jin Gam, and Dr. Connor Walters, who were always willing to take time out of their busy schedules to provide support and guidance throughout this process. I would also like to thank these individuals for their flexibility and understanding as I finished completed this thesis from halfway across the country. I also thank Dr. Anderson for introducing me to the posttraumatic growth concept and encouraging me to pursue this research.

I would also like to thank my wonderful family and friends, who provided support and encouragement when I needed it most. I am so blessed to have each and every one of you in my life. Without you, I would never have accomplished all I have today. I would like to extend a special thank you to my fellow grad students who not only provided guidance from their own experiences, but kept me sane with their friendship and humor throughout my graduate school career. I cannot imagine having shared this wonderful, though sometimes maddening, experience with anyone else.

This thesis is dedicated to the Smith family. Not only have I witnessed so many of you meet the challenges of chronic illness and loss with resiliency, I have seen you take these struggles and find a way to become even stronger. When it would be understandable to give in to stress or pain, you instead find ways to thrive. You are the faces of posttraumatic growth. Certainly, you were the inspiration for my thesis. 
However, you should know each member of your family inspires me in so many more ways every day. 


\section{CONTENTS}

ACKNOWLEDGMENTS

CONTENTS

CHAPTER

I. THE EFFECTS OF COMMUNITY SUPPORT ON POSTTRAUMATIC GROWTH OUTCOMES FOR PARENTS OF CHILDREN WITH CHRONIC ILLNESS 1

Abstract 1

Introduction 2

Methods $\quad 12$

Results 16

$\begin{array}{ll}\text { Discussion } & 21\end{array}$

Implications for Practice $\quad 28$

II. EXTENDED REVIEW OF LITERATURE 30

$\begin{array}{ll}\text { REFERENCES } & 46\end{array}$

APPENDIX A: $\quad$ Parent Recruitment Post $\quad 51$

APPENDIX B: $\quad$ Child Life Specialist Recruitment Post 52

APPENDIX C: $\quad$ Parent Demographic Information Survey 53

APPENDIX D: $\quad$ Posttraumatic Growth Inventory Electronic Copy 57

APPENDIX E: $\quad$ Perceived Community Support Questionnaire $\quad 59$

APPENDIX F: $\quad$ Child Life Specialist Survey $\quad 61$

APPENDIX G: $\quad$ Informed Consent Letter: Parents $\quad 64$ 


\title{
CHAPTER I
}

\section{THE EFFECTS OF COMMUNITY SUPPORT ON POSTTRAUMATIC GROWTH OUTCOMES FOR PARENTS OF CHILDREN WITH CHRONIC ILLNESS}

\begin{abstract}
Parents of children with chronic illnesses face many stressors on multiple fronts as a result of their child's care needs. Posttraumatic growth is positive psychological outcomes of stress for those who have experienced a traumatic event, such as the diagnosis of a child with a chronic illness. While much is known about the challenges of caring for a child with a chronic condition, there is little research on these parent's growth outcomes. Of the research that does exist, much focuses on internal predictors of posttraumatic growth, such as personality characteristics. The purpose of this study is to begin to investigate the connections between community belonging and the posttraumatic growth experiences of parents of children with chronic illnesses. This study was conducted using both quantitative analysis with the Posttraumatic Growth Inventory (PTGI; Tedeschi \& Calhoun, 1996) and the Perceived Community Support Questionnaire (PCSQ; Herreo \& Garcia, 2007), which were completed by parents, and qualitative analysis of child life specialists' observations of the role of creating community within the hospital and parents' growth experiences. While total PTGI and PCSQ scores were not significantly correlated, correlations between the community integration dimension of the PCSQ and certain factors of the PTGI suggests that greater community integration is
\end{abstract}


positively related to new possibilities, personal strength, and appreciation of life. Child life specialists' responses suggested that creating community through hospital programming contributes to parents' growth experiences.

\section{Introduction}

Parenting a child with a chronic illness or disability can be a source of continuous stress (Itzhaky \& Schwartz, 2000). Families of children with chronic conditions face unique challenges on the physical, financial, emotional, family and social levels (Branstetter, Domian, Williams, Graff, \& Piamjariyakul, 2008; Itzhaky \& Schwartz). These challenges are noticeably above and beyond the stressors faced by parents of typically developing healthy children and are often unexpected and unpredictable (Branstetter et al.). The multiple challenges can cause parents to experience depressive symptoms (Fauman et al., 2011), chronic grief (George, Vickers, Wilkes, \& Barton, 2007.), and levels of stress high enough to negatively affect parenting (Pedersen, Parsons, \& Dewey, 2004).

The experience of trauma can elicit painful emotional responses such as posttraumatic stress symptoms (Barakat, Alderfer, \& Kazak, 2006; Connerty \& Knott, 2013; Salter \& Stallard, 2004), posttraumatic stress disorder (PTSD; Li, Cao, Cao, Wang, \& Cui, 2012; Salter \& Stallard, 2004), and other threats to mental health (Toubman-BenAri, Findler, \& Kuint, 2010). In the last study, comparisons of three groups of mothers who had recently given birth were compared on several aspects of mental health and support (Toubman-Ben-Ari, Findler, \& Kuint). Mothers of preterm twins reported more 
negative outcomes of the associated stress compared to mothers of full-term twins and single babies. These responses included lower levels of mental health on a mental health inventory and more negative feelings toward their infant in a study on preterm twins.

However, despite the difficulties it brings, trauma can also lead to positive responses. In fact, in the same study on mother's responses after giving birth, mothers of preterm twins reported the highest levels of growth despite experiencing more negative feelings (Toubman-Ben-Ari, Findler, \& Kuint, 2010). In fact, many who report struggling with their trauma experience also report growth (Barakat et al., 2006; Connerty \& Knott, 2013; Konrad, 2006; Li et al., 2012; Phelps et al.). This apparent posttraumatic growth (PTG) is defined as an individual's experience of positive life changes as a result of a traumatic event (Dekel \& Nuttman-Schwartz, 2009; Tedeschi \& Calhoun, 1996). While related, PTG is not the same as resiliency, as resiliency refers to a return to the previous level of functioning and growth refers to an improvement in some area (Li et al., 2012).

\section{Post-Traumatic Growth}

It may seem counterintuitive for these positive outcomes to occur alongside the great stress that accompanies trauma. But, some studies (Li et al.; Salter \& Stallard, 2004) have even found that PTG and PTSD can coexist. The experience of stress actually seems to be important for the type of rumination, the process of questioning previously held beliefs or world views which were challenged by the individual's traumatic experience (Tedeschi, Calhoun, \& Cann, 2007), which makes growth possible (Calhoun 
\& Tedeschi, 2006; Taku, Tedeschi, Cann, \& Calhoun, 2009). When one experiences trauma, often their trauma experience does not fit with their previously held views of the world (Splevins, Cohen, Bowley, \& Joseph, 2010), including any beliefs an individual had about the world, such as a belief in a just world or their own luck (Spelvins et al.).

Individual's previous assumptions about themselves, about others, and about the predictability of the world are often challenged (Splevins et al., 2010). The individuals must attempt to bridge the gap between their previously held views and their trauma and post-trauma experience (Splevins et al.; Tedeschi \& Calhoun 1995, 2004). It is through this cognitive and affective struggle to make sense of the experience, not the trauma experience itself, that PTG occurs (Barr, 2011; Benetato, 2011; Connerty \& Knott, 2013; Splevins et al., 2010).

PTG has also been reported in parents of children facing medical challenges (Barr, 2011, Engelkemeyer \& Marwit, 2008; Li et al., 2012). One study on parents of children in a neonatal intensive care unit found that guilt-proneness in fathers was related to posttraumatic growth, though this relationship was mediated by positive-reappraisal coping (Barr). Positive reappraisal coping seems naturally related to growth as it balances stress with the belief of personal growth, reorganizing priorities, or changes in spiritual beliefs. Positive reappraisal coping was the strongest predictor of growth for both mothers and fathers in this study. In this same study, and inverted-U relationship was found between shame-proneness and growth for mothers meaning that moderate levels of shame-proneness were related to growth. Li et al. found that parents of children undergoing corrective surgery for congenital heart disease were more likely to experience 
growth if they had optimistic self-beliefs and high emotional intelligence. In this study, feelings of self-efficacy and perceived social support also had an indirect influence on growth. Parents also reported resilience and PTG after other health crises involving their children such as having of preterm twins (Taubman-Ben-Ari, Findler, \& Kuint, 2010) or having a child diagnosed with cancer (Barakat, Alderfer, \&Kazak, 2006; Rosenberg, Baker, Syrjala, Back, \& Wolfe, 2013; Yonemoto, Kamibeppu, Ishii, \& Tatezaki, 2012). Bereaved parents have also reported experiencing PTG (Engelmeyer \& Marwit). However, in this last study, grief intensity was found to have a negative correlation with PTG.

Support systems seem to play a role in facilitating the occurrence of PTG. Some believe coping efforts will often be played out in a social context (Li et al., 2012, Tedeschi \& Calhoun, 1998). Relationships seem to be an important resource to facilitate growth after trauma (Connerty \& Knott, 2013; Toubman-Ben-Ari, et al., 2010). Toubman-Ben-Ari et al., found that women with more external resources, such as support, experience more growth. Discussing the experience of trauma with others has been shown to increase the likelihood of PTG, whether the individual actually had the desire to disclose information, as reported by the participants (Taku et al., 2009). The reaction of the other person was shown to be important, however, as those who experienced encouragement, listening, or mutual exposure experienced more PTG. This study also found that mutual disclosure had a positive correlation with PTG and a negative correlation with distress. Some also view their trauma experience as something 
that allows them to reach out and help others in similar situations, and this seems to positively influence PTG as well (Connerty \& Knott; Johnson et al., 2009).

Professionals may also help facilitate growth. Providing supportive listening may provide individuals with an opportunity to identify support in their lives and give opportunities for growth (Konrad, 2006). Also, encouraging the individual who has experienced the trauma to share their story through life narrative may be valuable to the professionals, as it can help identify the individual's growth process. Professionals should not explicitly tell their patients to expect positive change or pressure them to find these positive outcomes, as not all individuals who have survived trauma experience PTG and this could actually be harmful to patients (Connerty \& Knott, 2013). This could cause patients to feel distressed if they do not experience growth.

\section{Community Support and Belonging}

According to Gasparini (2010), belonging is perceived to be vital to an individual's life and for feelings of certainty. Through interactions with groups such as family, organizations, and larger communities belonging shifts from the individual to the group, and vice-versa. Belonging influences actions through feelings of attachment to the various dimensions of belonging. Communities may consist of neighborhoods, cultural groups, religious organizations, sports teams, or other social groups (Herrero \& Garcia, 2007). Community may provide an individual with resources such as information and exposure to alternative means of support. Involvement in the community may lead to increased social support, as it results in more opportunities interactions with others and 
the formation of more relationships. Community involvement has been shown to increase feelings of empowerment (Itzhaky \& Schwartz, 2000). Similarly, community support has been shown to result in less depression over time (Herrero \& Garcia).

Interpersonal support and community belonging can have positive effects after a traumatic experience. Social support may allow individuals to reinterpret the situation and, as a result, improve their psychological well-being (Scrignaro et al., 2011). After a child's disabling injury or illness, mothers expressed the need for others, including family, community, and professionals, to acknowledge the difficult emotions parents experience (Konrad, 2006). A source of mutual support may be others who lived through the trauma (Johnson et al., 2009). Refugees who had been targeted due to their cultural group in their country of origin report that, because their trauma was not uncommon, it was seen as a shared experience. This social support seemed to normalize the experience and increase feelings of group belonging and cultural identity. Seeing others overcome the trauma may also have provided them with a sense of hope.

Dekel and Nuttman-Schwartz (2009) revealed that when comparing growth between individual's in two communities, one with especially strong community involvement, the research suggests that a stronger sense of belonging to one's country contributes to higher posttraumatic growth. For members of the community with high community involvement, belonging seemed to reduce stress symptoms. The study found that belonging allows individual's opportunities to cope by reducing isolation, normalizing the trauma, and encouraging healing. This suggests that individuals who have experienced trauma may be more likely to experience growth by creating 
connections with others, whether this is on a national, community, neighborhood, or other level.

One way to ensure parents have access to such a community environment is through the creation of support groups. Support groups provide opportunities for understanding, meaning-making, expression of feelings, and becoming a meaningful source of support for other group members (Papaikonomou, 2007). Support groups can also normalize parent's experiences as they hear stories from other parents which are similar to their own experience (Papaikonomou). Providing parents the opportunity to connect with other parents in similar situations can allow for both information sharing and emotional support (Coyne, 1995; Wei et al., 2012). Support groups are different than other types of community support because the support is intentional and, at least to some extent, structured (Papaikonomou).

Support groups have been shown to be of value to parents and caregivers in stressful experiences, such as a child's illness (Papaikonomou, 2007; Thurman, Jarabi, \& Rice, 2012; Wei et al., 2012). In a study involving caregivers of orphaned or otherwise vulnerable children in Kenya, those who participated in support groups reported less marginalization and improved family functioning (Thurman, Jarabi, \& Rice). In a case study of parents of a child who had been diagnosed with cancer, the parents noted that the support group they attended allowed them to connect with other parents who truly understood their situation (Papaikonomou, 2007). Support groups for caregivers of intellectually disabled family members have also been improve parents' physical and psychological health, decrease depression, decrease anxiety, and increase social, 
emotional and informational support (Wei et al, 2012). With technology, it is possible to provide parents some of the benefits of support groups even they cannot physically attend such groups. Online health communities have been linked to better understanding of and access to medical information, social support, and patient empowerment for those with illnesses (Johnston, Worrell, Di Gangi, \& Wasko, 2013). It seems likely that parents of children with illnesses would receive many of the same benefits.

In fact, in a study of parents of adolescents with type 1 diabetes, their needs and preferences relating to an online support resource, parents felt they would benefit from an online social support (Holtslander, Kornder, Lerourneau, Turner, \& Paterson, 2012). Parents in this study noted that not all parents are able to attend support groups but still wanted a place where they could share their experiences and talk to other parents who could understand to their experiences. Another option for initially providing supportive communities for parents of children with chronic illnesses would be organizing a parentto-parent support system, in which a parent who has more experience caring for a child with a chronic illness is connected with a parent of a recently diagnosed child to act as somewhat of a guide or mentor. Parent-to-parent support has been shown to reduce anxiety in mothers of children with chronic illnesses (Ireys, Chernoff, DeVet, \& Kim, 2001).

\section{Theoretical Framework}

Bioecological Theory (Bronfenbrenner, 1979, 1989) provides a useful framework for investigating the connections between community belonging and posttraumatic 
growth. This theory acknowledges the connections between human development and the various settings in which a person is either directly or indirectly connected (Kazak, 1989). Outcomes for parents of children with chronic illnesses will be affected not only by their own family interactions, but by interactions with many other groups, such as their healthcare system.

Bioecological theory assumes that human beings are both biological and social by nature (White \& Klein, 2008). As a result the theory focuses more on the physical environment and biophysical characteristics than many other theories. Therefore, it is a natural fit for examining the relationship between community belonging, which is directly related to environment, and the experience of posttraumatic growth. The theory also assumes that human beings depend both on the environment (e.g. for food) and, since we are social by nature, on other human beings (White \& Klein). Individuals are affected by multiple forces on multiple ecological levels. The levels are seen as nested within one another, meaning that the larger systems also contain the smaller systems (Bronfenbrenner, 1979).

The smallest system, the microsystem, refers to interactions between an individual and the present immediate environment. Next is the mesosystem, which refers to interactions between the different microsystems to which an individual belongs. This could include interactions between home and work for parents or, for parents of children with chronic illnesses, interactions between the home, work, and healthcare environments. The exosystem refers to environments which do not directly contain the individual, but still influence the individual and/or their current environment. For 
parents, their child's school is usually a part of the exosystem, as they are not typically present in the school yet are affected by the requirements of the school and their child's feelings about the school. The macrosystem does not refer to any physical environment, but rather the cultural influences which affect environments. This can include, but are not limited to, laws, cultural norms, and religious beliefs. The chronosystem was added later (Bronfenbrenner, 1989) and refers to the element of time and how timing also affects how an individual responds to events.

The Thinking-Feeling-Acting (TFA) Model has been used in counseling both to support the counselor-client relationship and to better understand an individual's response in different situations (Mueller, Dupuy, \& Hutchins, 1994). However, TFA can also be looked at as a sequence which can explain human behaviors, responses, and outcomes. For example, when one thinks their effort has resulted in their success, they will be more likely to experience the feeling of pride in their work, which will affect their effort and expectation for success in the future (Graham, 1994). Bernard Weiner (2012) points out, in relation to his Attribution Theory of Motivation, that thinking guides feelings and feelings guide actions or behaviors. This provides a useful framework for seeing how community support might affect the experience of posttraumatic growth. Community support will likely affect how one thinks about the challenges of caring for a child with a chronic illness, these thoughts will affect how one feels about the challenges, which will in turn affect their behaviors and, perhaps, their PTG outcomes.

The purpose of the quantitative portion of this study was to investigate potential relationships between community support and PTG using the Perceived Community 
Support Questionnaire (Herreo \& Garcia, 2007) and the Posttraumatic Growth Inventory (Tedeschi \& Calhoun, 1996) and to investigate the effectiveness of the use of these instruments to measure support and growth with this population. Based on the literature it was hypothesized that:

1. Community support would be positively correlated with posttraumatic growth

2. The PTGI and PCSQ instruments could be used to reliably measure PTG and community support for parents of children with chronic illnesses

Qualitative research regarding child life specialists' perceptions of community support and parents' posttraumatic growth within the hospital setting was also included. The purpose of this portion of the study was included as a preliminary investigation of the following questions:

1. What are child life specialists' perceptions of efforts to create communities within the healthcare setting for parents of children with chronic illness?

2. What are child life specialists' perceptions of connections between PTG in parents of children with chronic illnesses and efforts to create community within the healthcare setting?

\section{Methods}

The primary goal of this study was to investigate potential connections between community belonging and posttraumatic growth for parents of children with chronic illness. A separate instrument was also used with Child Life Specialist participants to 
investigate possible connections between creating community within the hospital environment and parent's experience of growth.

\section{Participants}

The sample population included two groups of participants: parents of children diagnosed with chronic illnesses and child life specialists. The first post requested assistance from child life specialists in sharing the survey with parents of children with chronic illnesses. Parent participants were required to be at least 18 years of age and have a child with a chronic illness. The second post requested child life specialists' participation. Child life specialist participants were required to be at least 18 years of age and currently working as a child life specialist in a hospital setting.

\section{Procedure}

Following approval from the University Institutional Review Board, two messages requesting research participants were posted to the child life forum on the Child Life Council's website: the first requesting assistance in recruiting parent participants and a second requesting the participation of child life specialists. Participants in both groups were recruited through a posting on the Child Life Forum on the Child Life Council website. The co-principal investigator is a member of the child life council and through this membership was able to post recruitment messages (Appendices A \&B) to the forum. The child life forum can be access by any paid members of the child life council, and is primarily used by child life specialists, child life assistants, and child life students. In the first post (refer to Appendix A), an email script containing a brief description of the 
research survey and a link to the informed consent letter and parent survey was provided. Child life specialists were asked to forward to script to parents of children with chronic illnesses. The second post (refer to Appendix B), briefly described the research survey and contained a link to the consent letter and child life specialist survey. Once consent was obtained participants completed the appropriate online survey for either parents (containing the parent demographic questionnaire, PTGI, and PCSQ) or child life specialists (containing the child life questionnaire and child life open ended questions).

\section{Measures}

Parent demographic questionnaire. Demographic information and data relating to the child's diagnosis/condition were collected through a demographic questionnaire (Appendix C) as part of the online survey. Participants reported current age, educational level, household income, and number of children. Information relating to their child's diagnosis was also reported and included the diagnosis given, time since diagnosis, and child's age at the time of diagnosis. Specific information about location (e.g. region, city of residence) was not collected for this study.

Posttraumatic growth inventory (PTGI). The PTGI (Appendix D) is a selfreport instrument used to measure the amount of perceived positive changes resulting from stress (Tedeschi \& Calhoun, 1996). It contains 21 statements to which participants self-report the level of change they experienced as result of a traumatic event. Responses are indicated on a 6-point Likert-type scale with answers ranging from "I did not experience this change as a result of my crisis" to "I experienced this change to a great 
degree as a result of my crisis." Total scores on the PTGI range from 0-105, with higher scores indicating a greater measurable level of growth. The PTGI also contains five subscales: relating to others, new possibilities, personal strength, spiritual change and appreciation of life.

Perceived community support questionnaire (PCSQ). The PCSQ (Appendix E) is a self-report instrument used to measure the amount of perceived sense of belonging one has in their community (Herreo \& Garcia, 2007). The instrument contains 14 statements to which participants indicate their level of agreement using a 5-point Likerttype scale with answers ranging from "Strongly Agree" to "Strongly Disagree." The questionnaire contains three subscales, Community Integration, Community Participation, and Community Organizations.

Child life demographic questionnaire. Demographic, professional, and hospital information were gathered through a demographic questionnaire (Appendix F) as part of the online survey. Participants reported information such as current age and education level. Participants also provided information such as number of years they had been a Child Life Specialist, which areas in the hospital they work, and size of the hospital.

Open ended questions for child life specialists. To obtain depth of understanding of specialist perspective, participants received a short questionnaire (Appendix F) containing open ended questions regarding hospital efforts to create community and their perception of growth experiences among parents of children with chronic illness. Questions included: 
1. Do you believe your hospital makes efforts to create community for parents with chronic illnesses within the hospital? If yes, please describe:

2. Have you witnessed parents of children with chronic illnesses who have experienced positive life changes as a result of the experience of parenting a child with a chronic illness? If yes, please describe changes you have seen without identifying any patient or parent:

3. If answered yes to the previous question: Do you believe hospital programming or efforts to create community within the hospital had an effect on the parent's experience of positive changes? If yes, please explain:

\section{Results}

\section{Quantitative Results}

Twelve parents or caregivers completed the questionnaire online through Select Survey. One participant did not complete the PCSQ Item "I identify with my community." Therefore, this participant's responses could not be included in analyses involving the PCSQ total or Community Integration Dimension. However her responses were included analyses involving the Community Participation and Community Organization Dimensions of the PCSQ, the PTGI, and all PTGI factors. The PTGI was found to be a highly reliable instrument for this population $(\alpha=0.91)$. However, reliability was low for the PCSQ ( $\alpha=0.408)$, although the small sample size may have influenced this result. All participants were mothers of a child with a chronic illness, with the exception of one participant who was a female caregiver with legal custody of 
the child. Participants were between 26-60 years of age, with most reporting to be either between 48-55 years $(n=5)$ or $41-47$ years $(n=4)$. All were married at the time of this study. $25 \%(n=3)$ were currently attending college, approximately $42 \%(n=5)$ had a college degree, and approximately $33 \%$ had completed a master's degree. This participant sample was relatively homogeneous in regards to income with approximately $58 \%(n=7)$ of participants making over $\$ 4000$ per month. Percent of patients reporting monthly incomes between $\$ 2000-3000$ and $\$ 3000-4000$ was approximately $17 \%(n=2)$ each and one participant reported a monthly income between $\$ 1000-2000$. There was little diversity in ethnicity within this sample with only one participant identifying as Asian and the remaining identifying as White. Time since their child's diagnosis ranged from 3 weeks- 21 years. Panhypopituitarism was reported by all but one of the participants as a diagnosis for their child, though it was often reported to be comorbid with other diagnoses.

Correlation analysis was run between the PTGI and PCSQ to analyze possible relationships between the two scales. No significant correlation was found between the PTGI and PCSQ (Pearson's r=3.8, $\mathrm{p}>.05)$; the low sample size $(\mathrm{n}=11)$ likely affected the results of this correlation. However, significant correlations were found between one of the subscales in the PCSQ and three of the subscales of the PTGI. Specifically, the community integration dimension of the PCSQ was correlated with the New Possibilities $(r(9)=0.607, p<0.05)$, Personal Strength $(r(9)=0.518, p<0.05)$, and Appreciation of Life $(r(9)=0.598, p<0.05)$ factors of the PTGI. 


\section{Qualitative Results}

The child life survey was completed by 24 child life specialists. However, two participants completed the survey after analysis had already commenced and their responses were not included in this study. As a result, 22 child life participant responses were included in this research. Responses to the open-ended questions on the child life specialists' survey were coded using the open coding method (Strauss \& Corbin, 1998), by the principal and co-principal investigator until agreement was reached. A third committee member then reviewed the coding separately for further consensus. The child life specialists' responses to the survey questions showed an overwhelmingly positive view of efforts to create community for parents within their hospitals and the effects of such communities for parents. Of those who did not report a positive view of created communities $(n=3)$, two reported challenges in creating communities within their hospital; the third did not provide an explanation. After coding participant responses, the five most common themes which occurred were: community expansion, learning, community awareness, family functioning, and advocacy. A description of each of these themes is provided below.

Community expansion. In this study, community expansion is defined as either becoming involved in or creating a new community or creating new relationships within a community in which one is already involved. Child life specialists mentioned support groups, parent-to-parent programs, family advisory councils, special programming, and special events as ways parents were able to expand their communities and relationships. These new or expanded communities were seen as sources for parents to give/receive 
support and as normalizing their experience. Some specialists also reported community expansion without the creation of such intentional programming for parents who formed relationships with other parents they encountered during their healthcare experience.

Learning. In this study learning is defined as a new or improved understanding. While two child life specialists reported formal learning opportunities for parents, in the form of classes regarding care of a child with a chronic illness, they were more likely to report informal forms of learning for parents. Some of this learning was seen as a direct result of caring for a child with chronic illness and some was seen as a result of the support received from others, especially other parents, though support from the child's healthcare team was also viewed as important. In both circumstances, learning was reflected in the child life specialists' responses in relationship to perspective change, lifestyle change, development of coping skills, and development of skills related to the care of their child with a chronic illness.

Family functioning. In this study, family functioning can be defined as the way a family interacts with and responds to one another. Child life specialists expressed they had observed improved family functioning in parents and families both as a result of raising a child with a chronic illness and through the support they received from other parents. The most commonly reported change in family functioning was related to relationships within the family; specifically families were seen as having grown closer. However, one specialist also noted a change in communication within families; specifically, the parents were seen as being more open with their children about the patient's health and healthcare. 
Advocacy. In this study, advocacy can be defined providing support for a person or cause. This was most commonly reflected in child life specialists' reports that parents became involved in organizations or groups which raised awareness, support, or funds for either their child's specific diagnosis or children with chronic illnesses in general. One child life specialist reported that she had witnessed parents create their own organizations or groups. Another child life specialist's response reflected that parents advocated for other parents, as they sometimes lead the support groups. A third child life specialist discussed observing a different kind of advocacy, which occurs when parents stand up for themselves and their child.

Community awareness. The last theme, community awareness, differs from the others in the sense that it is related to the views of the child life specialists in the study rather than their observations of parents of children with chronic illnesses. In this study, community awareness can be defined as an expressed belief in the importance of community within the hospital or an expressed understanding that parents find community within the hospital. Child life specialists showed community awareness in their responses in three ways: expressed desire the provide communities for parents within their hospital, expressed knowledge of resources which foster community, and expressed knowledge of the influence of spaces within their hospital in creating community. The expressed desire to provide communities was seen in two responses. In one of these responses the child life specialist expressed a desire for an intentional community (a support group, in this case) for parents in her hospital. The other respondent noted several ways the hospital where she works attempts to create 
community for parents, but expressed a belief that could still be more added. The responses regarding knowledge of resources which foster community reflected staff efforts to provide support and resources to parents, therefore including parents in the medical community. Lastly, in regards to the influence of space, one respondent noted that spaces in her hospital were designed find community (e.g. family lounge, family resource center, lobby areas).

\section{Discussion}

While the current research did not find a correlation between overall PTGI and PCSQ scores, a positive relationship was found between the Community Integration dimension and the New Possibilities, Personal Strength, and Appreciation of Life factors of the PTGI. This suggests that those with a greater sense of belonging or identification to their communities are able to have, or perceive, more opportunities, see themselves as stronger individuals, and view their lives more positively. According to the TFA Model (Mueller, Dupuy, \& Hutchins, 1994), a person's thoughts will affect their feelings, and their feelings will affect their action. A person's feeling of belonging in a community will then likely affect how they think about the task of caring for a child with a chronic illness. This thinking will affect other areas of their lives, which can explain why parents with higher scores on the community integration dimension of the PTGI also showed growth in new possibilities, personal strength, and appreciation of life.

According to Bronfenbrenner's Bioecological Theory $(1979,1989)$ human beings are dependent on other people because we are social beings. It is believed that coping 
efforts occur in a social context (Li et al., 2012; Tedeschi \&Calhoun, 1998). In fact, a study by Toubin-Ben-Ari et al. (2010) found that women with more external resources experience more growth. The results of this research, which suggest community belonging increases the likelihood of certain types of PTG, support the belief the social resources have an impact on coping. According to Bronfenbrenner, all systems in the ecological system are related. It is not surprising that greater feelings of belonging in the mesosystem seem to affect an individual and their microsystem.

These findings are further supported by the qualitative results in this study. Child life specialists' responses to open ended questions regarding the hospital community and PTG revealed five themes: community expansion, learning, family functioning, advocacy, and community awareness. In relation to community expansion, child life specialists saw hospital programming such as support groups, parent-to-parent groups, family advisory councils, and special events, as sources for parents to give and receive support. Child life specialists reported this as something which helped parents normalize their experiences. This also relates to the TFA model, because such programming affects a parents thinking, which allows them to reframe their situation more positively (feeling), and can potentially lead to PTG. This similarly relates to Bioecological Theory, because hospital programming creates a new environment within the ecosystem. Parents are able to use their experiences in one environment to influence their thinking in other environments. These connections between microsystems show the power of the mesosystem. 
In relation to the theme of learning, most child life specialists reported observing this type of growth largely took place through informal learning opportunities for parents. While some participants reported formal learning opportunities in the form of classes and educational programs for parents, this was less common. Child life specialists reported parents learned to change their perspective or lifestyle, coping skills, and skills related to the care of children with a chronic illness. As pointed out by participant 4, some of these changes are likely a direct result of caring for a child with a chronic illness. This is consistent with previous research which suggests that the rumination that that takes place after a stressful experience, such as the diagnosis of a child with a chronic illness, results in the type of changes in thinking which make growth possible (Tedeschi, Calhoun, \& Cann, 2007). However many child life specialists, including this same participant, believed learning also took place as a result of the support they received from others. This again supports the belief that coping takes place on the social stage. Support from other parents who have a child with chronic illness was seen as especially important. This is consistent with previous research which reports that mutual disclosure increases the likelihood of PTG (Taku et al., 2009). It is also supports research which found that talking with those with similar experiences to be therapeutic (Johnson et al., 2009). Support from the healthcare team was also seen as important factor in parents learning experience.

The third theme, family functioning, was reflected in child life specialists' reports that they had observed families becoming closer as a result of raising a child with a chronic illness and the support they received from other parents. Such experiences of 
growth related to the "Relationships with Others" factor of the PTGI. Interestingly, no connections were found between the PCSQ nor any of its dimensions to the "Relationships with Others" factor of the PTGI in this sample. Future research should further investigate possible connections between relationships with others and community support for parents of children with chronic illnesses using a larger sample size. The observed connections between supportive programming for parents, such as support groups and parent-to-parent programs, again support the importance of hospitalbased support programs to the mesosystem of parents of children with chronic illnesses. Based on child life specialists' observations, the support parents receive in the hospitalbased program microsystem seems to have a positive impact on their home/family microsystem. This also supports the TFA model because an individual's thinking seems to be transformed during support groups, as talking with other parents normalizes their own experiences. This transformation in thinking reframes the way they feel about the challenges related to raising a child with a chronic illness, which in turn affects their interactions with their family.

Advocacy was the fourth theme in child life specialists' responses. CCLS participants reported that they have seen parents use their experience to provide support to other parents or organizations. These programs raised awareness, support, and funds for specific illnesses, chronic illnesses in general, and parents of children with chronic illnesses. Parents even created their own organizations or supported other parents by leading a session of their support group. Advocating for others in similar situations fits into the "New Possibilities" and "Personal Strength" factors of the PTGI, both of which 
were connected to the Community Integration dimension of the PCSQ. It seems that parents recognize the opportunity to support others and their ability to provide such support through their experiences of caring for a child with a chronic illness. In a study of refugees in the UK, some participants saw their previous oppression means to assist new refugees arriving from their country though their work as translators or with refugee organizations (Johnson et al., 2009). The refugees work not only provided a sense of purpose resulting from their trauma, but also connected them to others who had faced similar oppression in their country of origin, thus allowing them to normalize their experience. It seems likely the parents' advocacy efforts could provide a similar sense of purpose and source of normalization. Participant 16 referred to a different type of advocacy, stating "...families learn to speak up for themselves and for their children...," which is an example of self-advocacy. Both types of advocacy consistent with the TFA model because the parents' thoughts and feeling are changed through their experiences with their child and the support they receive. These changes in thoughts and feelings then seem to result in action in the form of supporting others and standing up for themselves. This is, once again, example of the mesosystem and the influence one microsystem can have in other areas of life.

The final theme that emerged, community awareness, refers to the child life specialists' own perceptions of creating communities for parents of children diagnosed with chronic illnesses. Child life responses related to the effects of creating such communities was overwhelmingly positive. Some expressed hope that supportive communities for parents, such as support groups, would be created in their hospital and 
others hoped to expand on already existing programming for parents. Other child life specialists expressed their knowledge of outside resources which serve to provide communities for parents of children with chronic illnesses and the positive experience parents have had in these groups. One child life specialist noted how spaces in the hospital, such as family lounges or lobby areas, where she works were designed to foster community and help parents find support. These responses reflect the beliefs that supportive communities for parents can be created within the healthcare environment and such communities are a valuable resource for parents.

The primary limitation of this study was the small sample size in the parent participant sample. Future research should further investigate the connections between posttraumatic growth and community support for parents of children with chronic illnesses. However, the connections found between the community integration dimension and the New Possibilities, Personal Strength, and Appreciation of Life factors of the PTGI are promising. It should also be noted that child life specialists' responses in this study reflect only their perception of parents' growth through community support. Further research is needed to investigate whether these beliefs and consistent with parents' own perceptions. The parent sample was very homogeneous is race, SES, education, and their child's diagnosis, therefore results may not be transferable to other populations. Future research should include a more diverse sample. Lastly, the reliability of the PCSQ was not high ( $\alpha=0.408)$. The small sample size may have contributed to the poor reliability. Future research should investigate the use of this instrument with this population using a larger sample size. In conclusion, this research 
suggests that community belonging increases the occurrence of positive outcomes resulting from caring for a child diagnosed with a chronic illness. Specially, parents with a greater sense of community belonging are more likely to see new opportunities, have a greater sense of personal strength, and a greater appreciation of life. These positive outcomes in no way lessen the stress associated with having a child diagnosed with a chronic illness. As previously stated, some level of stress actually must occur in order for PTG to be possible (Johnson et al., 2009; Li et al., 2012; Phelps et al., 2009; Splevins et al., 2010; Toubman-Ben-Ari, 2010). However, it suggests that parents with greater community support are able to cope with the stressors in a way which allows them to frame their experiences more positively. Consistent with Bronfenbrenner's Bioecological Theory, the support parents receive in one environment will have positive effects in other environments the parent occupies. This is an example of the mesosystem, which refers to the connections between an individual's microsystems. Child life specialists' accounts of parents PTG reflect the TFA model. Participant 9 illustrated the TFA sequence with her response, "I think some of it is the nature of the chronic illness experience - it changes your perspective on a lot of things as you are forced to view life from a different vantage point. However, I think that as parents are making this shift in perspective, they need the support of staff and other families who can understand what they are going through. Change is difficult to make in an isolated vacuum. Parents may be inclined to change, but need the reassurance that this is normal and that although some things may change, others may stay the same and that can be [the] feeling that helps ground you when everything else seems to be in flux." Another child life specialist, participant 2, provided a similar example, "It was evident that through this support group the parents were able 
to connect and shift their perspective of themselves and their family." The support parents received seemed to normalize their experiences and reframe their thinking. This normalization seemed to increase parents' positive feelings about their experiences as they saw new possibilities and felt greater internal strength. These feelings likely influenced their actions to advocate for themselves and others in similar situations. This research suggests that healthcare staff should strive to create communities, such as support groups or parent-to-parent programs, for the parents of the children with chronic illnesses. Such programming seems to have a positive effect of parents coping. Since the results of such programming seem to be transferred to the home environment, it seems probable that the patients will benefit indirectly from the programming. This is consistent with Bronfenbrenner's exosystem, which refers to environments that do not directly contain the individual but still affect the individual.

\section{Implications for Practice}

Results of this study reflect the importance of including supportive programming which creates community for parents of children with chronic diagnoses as an element of family centered care. These parents face many daily stressors on the physical, emotional, and social levels (Branstetter, Domian, Williams, Graff, \& Piamjariyakul, 2008; Itzhaky \& Schwartz). However, this research suggests that programming, such as support groups, parent-to-parent programs, and special events for parents, increases the likelihood that parents will experience positive growth as a result of their experiences. These supports were seen as having a positive effect on family functioning. Therefore, programming for parents will likely also have positive results for the patient with the chronic illness. 
Patient care takes place in the family environment (Papaikonomou, 2007). For this reason, it is important to provide support and psychosocial care for each family member. The potential benefits for parents of children with chronic illnesses should not be overlooked. 


\section{CHAPTER II}

\section{EXTENDED REVIEW OF LITERATURE}

Parenting a child with a chronic illness or disability can be a source of continuous stress (Itzhaky \& Schwartz, 2000). Families of children with chronic conditions face unique challenges on the physical, financial, emotional, family and social levels (Branstetter, Domian, Williams, Graff, \& Piamjariyakul, 2008; Itzhaky \& Schwartz). These challenges are noticeably above and beyond the stressors faced by parents of typically developing healthy children and are often unexpected and unpredictable (Branstetter et al.,). Parenting a child with a chronic illness or disability affects family dynamics (Phelps, McCammon, Wuensch, \& Golden, 2009), roles within the family, communication (Branstetter et al., 2008), marital satisfaction (Phelps et al., 2009), connections to others (Branstetter et al.), and overall family functioning and survivorship (Branstetter et al.; Rosenberg, Baker, Syrjala, Back, \& Wolfe, 2013).

Parental stress levels may be influenced by severity of the illness (Pedersen, Parsons, \& Dewey, 2004), visibility of the condition, level of impairment (Pedersen et al., 2004), hospitalizations (Fauman et al., 2011; Pedersen et al.), medical history (George, Vickers, Wilkes, \& Barton, 2007), deterioration in child's health (George et al.), deterioration in parental health, caretaking demands (Pedersen et al.), other's reactions to their child (George et al.), and support (Pedersen et al.). Such multiple challenges can cause parents to experience depressive symptoms (Fauman et al.), chronic grief (George 
et al.), and levels of stress high enough to negatively affect parenting (Pedersen et al.). However, many parents do indeed find ways to effectively cope with the challenges brought by having children with a chronic illness. For instance, those in a caretaker role who use positive religious coping found more satisfaction from their caregiving responsibilities (Pearce, Singer, \& Prigerson, 2006). Other parents have also reported positive outcomes related to parenting a child with chronic illness such as enrichment, empowerment (Phelps et al., 2009), and benefit or meaning finding (Rosenberg et al., 2013).

\section{Posttraumatic Growth}

The experience of trauma can elicit painful emotional responses such as posttraumatic stress symptoms (Barakat, Alderfer, \& Kazak, 2006; Connerty \& Knott, 2013; Salter \& Stallard, 2004), posttraumatic stress disorder (PTSD) (Li, Cao, Cao, Wang, \& Cui, 2012; Salter \& Stallard, 2004), and other threats to mental health (Toubman-Ben-Ari, Findler, \& Kuint, 2010). In the last study, comparisons of three groups of mothers who had recently given birth were compared on several aspects of mental health and support. Mothers of preterm twins reported more negative outcomes of the associated stress compared to mothers of full-term twins and single babies. These responses included lower levels of mental health on a mental health inventory and more negative feelings toward their infant.

However, despite the difficulties it brings, trauma can also lead to positive responses. In fact, in the same study on mother's responses after giving birth, mothers of 
preterm twins reported the highest levels of growth despite experiencing more negative feelings (Toubman-Ben-Ari, Findler, \& Kuint, 2010). Posttraumatic growth (PTG) is defined as an individual's experience of positive life changes as a result of a traumatic event (Dekel \& Nuttman-Schwartz, 2009; Tedeschi \& Calhoun, 1996). Also, PTG seems to be experienced in all cultures, but the types of growth experienced may vary by culture (Splevins, Cohen, Bowley, \& Joseph, 2010). While related, PTG is not the same as resiliency, as resiliency refers to a return to the previous level of functioning and growth refers to an improvement in some area (Li et al., 2012). These positive changes do not negate the pain associated with trauma. In fact, some level of stress seems to be necessary in order to experience PTG (Johnson, Thompson, \& Downs, 2009; Li et al.; Phelps et al., 2009; Splevins et al., 2010; Toubman-Ben-Ari et al., 2010). Many who report struggling with their trauma experience also report growth (Barakat et al., 2006; Connerty \& Knott, 2013; Konrad, 2006; Li et al., 2012; Phelps et al.;). Phelps et al. found that stress and enrichment both occur for parents of children with autism spectrum disorders and that both of these factors predicted PTG. The study by Barakat et al. found that a positive relationship between posttraumatic stress symptoms and PTG. This same study also found a positive relationship between both perceived life threat (both past and present) and treatment intensity with PTG. Some studies (Li et al.; Salter \& Stallard, 2004) have even found that PTG and PTSD can coexist. Li et al. found that parents with children going through corrective surgery for a congenital malformation who met the criteria for PTSD also reported more growth. Similarly, in a study on children who survived traffic accidents, 37\% of the participants who had reported PTG also met the criteria for PTSD. 
It may seem counterintuitive for these positive outcomes to occur alongside the great stress that accompanies trauma. But, the experience of stress seems to be important for the type of rumination which makes growth possible (Calhoun \& Tedeschi, 2006; Taku, Tedeschi, Cann, \& Calhoun, 2009). Rumination is the process of questioning previously held beliefs or world views which were challenged by the individual's traumatic experience (Tedeschi, Calhoun, \& Cann, 2007). Though the relationship between stress and trauma is not fully understood (Dekel \& Nuttman-Shwartz, 2009), rumination appears to play a role because it causes one to reflect on the trauma in order make sense of the situation and develop new life views. When one experiences trauma, often their trauma experience does not fit with their previously held views of the world (Splevins, Cohen, Bowley, \& Joseph, 2010). Previously held world views refer to any beliefs an individual had about the world, such as a belief in a just world or their own luck (Spelvins et al.).

Individual's previous assumptions about themselves, about others, and about the predictability of the world are often challenged (Splevins et al., 2010). The individuals must attempt to bridge the gap between their previously held views and their trauma and post-trauma experience (Splevins et al.; Tedeschi \& Calhoun 1995, 2004). This may help explain why those who perceive an event as more threatening also tend to experience more growth (Dekel \& Nuttman-Schwartz, 2009). It is through this cognitive and affective struggle to make sense of the experience, not the trauma experience itself, that PTG occurs (Barr, 2011; Benetato, 2011; Connerty \& Knott, 2013; Splevins et al., 2010). 
Various personality characteristics and coping styles have also been identified as being related to PTG (Connerty \& Knott, 2013; Dekel \& Nuttman-Schwartz, 2009; Gall, Charbonneau, \& Florack, 2011; Kunst, 2010; Scrignaro, Barni, \& Magrin, 2011; Seidmahmoodi, Rahimi, \& Mohamadi, 2011). In a study by Kunst, high affective personality styles, defined as being both high in positive affect (the ability to keep a positive outlook) and negative affect (the tendency to experience negative emotions and self-evaluations), have been found to be linked to both PTG and PTSD symptoms. Whereas self-destructive personality style, defined as being low in positive affect and high in negative affect, was linked only to the PTSD symptoms. This same study found that PTG was most likely to occur when positive and negative affect occur together, as stated earlier concerning perceptions. Optimism and novelty-seeking also seem to increase the occurrence of PTG, perhaps because these characteristics are associated with flexibility in problem-solving (Seidmahmoodi, et al.). Active-coping, particularly problem-focused coping, is also associated to PTG (Scrignaro et al.).

In a study by Connerty \& Knott (2013), cancer patients identified elements of active coping, such as information-seeking and making life-style changes, as being related to the occurrence of positive changes. Such coping mechanisms may help individuals feel a greater since of control over their stressors. With chronic illness, at certain times avoidance may be an effective coping strategy, as it can allow individuals to refocus their attention so that their diagnosis is not the dominating influence on their lives (Gall et al., 2011). 
Religious coping also influences the occurrence of PTG (Gall et al., 2011;

Johnson et al., 2009; Seidmahmoodi et al., 2011). Religious coping may help refocus attention, reappraise situations as challenges rather than threats, and provide a greater since of control (Gall et al., 2011; Johnson et al., 2009; Seidmahmoodi et al.). Religious beliefs can also influence growth through framing the traumatic event as something which happens for a reason and would be compensated for later (Johnson et al., 2009). A study by Seidmahmoodi et al., found that intrinsic religious orientation (orthodox beliefs) was positively related to posttraumatic growth while extrinsic orientation (viewing religion as a way to meet goals) was only linked to growth if the orientation was personal rather than social. For those experiencing chronic illness, time since diagnosis and specific types of religious coping affect the experience of PTG as well (Gall et al., 2011). In this latter study, researchers found that high levels of religious salience were linked to poorer growth outcomes for cancer patients 24 months after their surgeries. Women in this study who coped with stress by surrendering control to God were less likely to experience growth. This is perhaps related to the differences in growth between those with intrinsic versus extrinsic orientations found by Seidmahmoodi et al. Gall et al. also found that negative religious coping, such as anger directed at God, can facilitate growth as long as individuals are actively engaged in their struggle with trauma and eventually move to a more positive view.

Growth in parents of children with illness. PTG has also been reported in parents of children facing medical challenges (Barr, 2011, Engelkemeyer \& Marwit, 2008; Li et al., 2012). One study on parents of children in a neonatal intensive care unit 
found that guilt-proneness in fathers was related to posttraumatic growth, though this relationship was mediated by positive-reappraisal coping (Barr). Positive reappraisal coping seems naturally related to growth as it balances stress with the belief of personal growth, reorganizing priorities, or changes in spiritual beliefs. Positive reappraisal coping was the strongest predictor of growth for both mothers and fathers in this study. In this same study, and inverted-U relationship was found between shame-proneness and growth for mothers meaning that moderate levels of shame-proneness were related to growth. Li et al. found that parents of children undergoing corrective surgery for congenital heart disease were more likely to experience growth if they had optimistic self-beliefs and high emotional intelligence. In this study, feelings of self-efficacy and perceived social support also had an indirect influence on growth. Parents also reported resilience and PTG after other health crises involving their children such as having of preterm twins (Taubman-Ben-Ari, Findler, \& Kuint, 2010) or having a child diagnosed with cancer (Barakat, Alderfer, \&Kazak, 2006; Rosenberg, Baker, Syrjala, Back, \& Wolfe, 2013; Yonemoto, Kamibeppu, Ishii, \& Tatezaki, 2012). Bereaved parents have also reported experiencing PTG (Engelmeyer \& Marwit). However, in this last study, grief intensity was found to have a negative correlation with PTG.

Growth and support. Support systems seem to play a role in facilitating the occurrence of PTG. Some believe coping efforts will often be played out in a social context (Li et al., 2012, Tedeschi \& Calhoun, 1998). Relationships seem to be an important resource to facilitate growth after trauma (Connerty \& Knott, 2013; ToubmanBen-Ari, et al., 2010). Toubman-Ben-Ari et al., found that women with more external 
resources, such as support, experience more growth. Another study found that patients who are supported by their caregivers have been shown to experience more PTG (Scrignaro et al., 2011). Discussing the experience of trauma with others has been shown to increase the likelihood of PTG, whether the individual actually had the desire to disclose information as reported by the participants (Taku et al., 2009). The reaction of the other person was shown to be important, however, as those who experienced encouragement, listening, or mutual exposure experienced more PTG. This study also found that mutual disclosure had a positive correlation with PTG and a negative correlation with distress. The relationship between social support and PTG may be mediated by posttraumatic stress symptoms (Li et al., 2012). Some also view their trauma experience as something that allows them to reach out and help others in similar situations, and this seems to positively influence PTG (Connerty \& Knott; Johnson et al., 2009).

Professionals may also help facilitate growth. Providing supportive listening may provide individuals with an opportunity to identify support in their lives and give opportunities for growth (Konrad, 2006). Also, encouraging the individual who has experienced the trauma to share their story through life narrative may be valuable to the professionals, as it can help identify the individual's growth process. Professionals also should not explicitly tell their patients to expect positive change or pressure them to find these positive outcomes, as not all individuals who have survived trauma experience PTG and this could actually be harmful to patients (Connerty \& Knott, 2013). This could cause patients to feel distressed if they do not experience growth. It also may be more helpful 
to understand that the positive outcomes are a result of the process of finding meaning, rather than from the loss itself (Konrad).

\section{Community Belonging/Support}

According to Gasparini (2010), belonging is perceived to be vital to an individual's life and for feelings of certainty. Through interactions with groups such as family, organizations, and larger communities belonging shifts from the individual to the group, and vice-versa. Belonging may be territorial, which involves a created meaning and symbolism to landscapes, such as borders, and a sense of attachment to these landscapes. This type of belonging involves the attachment on may feel to a country, state, city, neighborhood or another physical space. Values and shared ideas can also create feelings of belonging, such as belonging to a country or an ethnic group. This is cultural belonging. Relationships also create meaning and provide identity, resulting in social belonging. An individual does not experience these different belongings in isolation of the others, though one may be more apparent than others. Belonging may be localized, meaning the local community becomes the main reference point for the individual. However, it is not uncommon now for belonging to occur as a more globalized or cosmopolitan experience which may be experienced along with the attachment to local spaces. Belonging influences actions through feelings of attachment to the various dimensions of belonging.

Communities may consist of neighborhoods, cultural groups, religious organizations, sports teams, or other social groups (Herrero \& Garcia, 2007). 
Community may provide an individual with resources such as information and exposure to alternative means of support. Involvement in the community may lead to increased social support, as it results in more interactions with others and the formation of more relationships. Community involvement has been shown to increase feelings of empowerment (Itzhaky \& Schwartz, 2000). Belonging to a community results in feelings of loyalty and, as an individual integrates into the community, they identify both with other individuals in the community and the community as a whole (Gasparini, 2010). Community support has been shown to result in less depression over time (Herrero \& Garcia).

Interpersonal support and community belonging can have positive effects after a traumatic experience. Social support may allow individuals to reinterpret the situation and, as a result, improve their psychological well-being (Scrignaro et al., 2011). Scrignaro et al. also revealed that it is important in relationship to PTG that cancer patients receive encouragement to find their proactive nature. After the birth of fullterm twins, maternal grandmother's support was found to be important in relation to PTG (Toubman-Ben-Ari et al., 2010). Interestingly, this type of support did not have the same affect for all, specifically mothers of pre-term twins or single babies. After a child's disabling injury or illness, mothers expressed the need for others, including family, community, and professionals, to acknowledge the difficult emotions parents experience (Konrad, 2006). Another study found that married individuals experienced more PTG than unmarried participants, suggesting that mutual support is beneficial after trauma (Seidmahmoodi et al., 2011). 
Another source of mutual support may be others who lived through the trauma (Johnson et al., 2009). Refugees who had been targeted due to their cultural group in their country of origin report that, because their trauma was not uncommon, it was seen as a shared experience. This social support seemed to normalize the experience and increase feelings of group belonging and cultural identity. Seeing others overcome the trauma may also have provided them with a sense of hope. Individuals in this study seemed to find mutual support by helping others who had experienced similar trauma through their work with interpreting services or refugee organizations.

Dekel and Nuttman-Schwartz (2009) revealed that when comparing growth between individual's in two communities, one with especially strong community involvement, the research suggests that a stronger sense of belonging to one's country contributes to higher posttraumatic growth. For members of the community with high community involvement, belonging seemed to reduce stress symptoms. The study found that belonging allows individual's opportunities to cope by reducing isolation, normalizing the trauma, and encouraging healing. This suggests that individuals who have experienced trauma may be more likely to experience growth by creating connections with others, whether this be on a national, community, neighborhood, or other level. Community belonging also was particularly beneficial for those who perceived there to be greater threats. 


\section{Support Groups}

It seems clear that community support can protect parents against some of the negative effects of the stress of caring for a child with a chronic illness. One way to ensure parents have access to such an environment is through the creation of support groups. Support groups provide opportunities for understanding, meaning-making, expression of feelings, and becoming a meaningful source of support for other group members (Papaikonomou, 2007). Support groups can also normalize parent's experiences as they hear stories from other parents which are similar to their own experience (Papaikonomou). Providing parents the opportunity to connect with other parents in similar situations can allow for both information sharing and emotional support (Coyne, 1995; Wei et al., 2012). Support groups are different than other types of community support because the support is intentional and, at least to some extent, structured (Papaikonomou).

Support groups have been shown to be of value to parents and caregivers in stressful experiences, such as a child's illness (Papaikonomou, 2007; Thurman, Jarabi, \& Rice, 2012; Wei et al., 2012). In a study involving caregivers of orphaned or otherwise vulnerable children in Kenya, those who participated in support groups reported less marginalization and improved family functioning (Thurman, Jarabi, \& Rice). This study also found that children of parents or caregivers in support groups showed more positive behaviors and less negative behaviors than those whose caregivers did not participate in support groups. In a case study of parents of a child who had been diagnosed with cancer, the parents noted that the support group they attended allowed them to connect with other 
parents who truly understand their situation (Papaikonomou, 2007). The father in this study also felt that the group allowed them share the many feelings associated with caring for a child with cancer and to normalize their own experience. Support groups for caregivers of intellectually disabled family members have also been improve parents' physical and psychological health, decrease depression, decrease anxiety, and increase social, emotional and informational support (Wei et al.). With technology, it is possible to provide parents some of the benefits of support groups even they cannot physically attend such groups. Online health communities have been linked to better understanding of and access to medical information, social support, and patient empowerment for those with illnesses (Johnston, Worrell, Di Gangi, \& Wasko, 2013). It seems likely that parents of children with illnesses would receive many of the same benefits. In fact, in a study of parents of adolescents with type 1 diabetes and their needs and preferences relating to an online support resource, parents felt they would benefit from an online social support (Holtslander, Kornder, Lerourneau, Turner, \& Paterson, 2012). Parents in this study noted that not all parents are able to attend support groups but still wanted a place where they could share their experiences and talk to other parents who could understand to their experiences. Another option for initially providing supportive communities for parents of children with chronic illnesses would be organizing a parent-to-parent support system, in which a parent who has more experience caring for a child with a chronic illness is connected with a parent of a recently diagnosed child to act as somewhat of a guide or mentor. Parent-to-parent support has been shown to reduce anxiety in mothers of children with chronic illnesses (Ireys, Chernoff, DeVet, \& Kim, 2001). 


\section{Theoretical Application}

Bioecological theory. Bioecological Theory (Bronfenbrenner, 1979, 1989) provides a useful framework for investigating the connections between community belonging and posttraumatic growth. This theory acknowledges the connections between human development and the various settings in which a person is either directly or indirectly connected (Kazak, 1989). Outcomes for parents of children with chronic illnesses will be affected not only by their own family interactions, but by interactions with many other groups, such as their healthcare system.

Bioecological theory assumes that human beings are both biological and social by nature (White \& Klein, 2008). As a result the theory focuses more on the physical environment and biophysical characteristics than many other theories. Therefore, it is a natural fit for examining the relationship between community belonging, which is directly related to environment, and the experience of posttraumatic growth. The theory also assumes that human beings depend both on the environment (e.g. for food) and, since we are social by nature, on other human beings (White \& Klein). This would suggest that parents in this study may use their communities as a source of important social resources. Another assumption is that interactions are organized proximally (White \& Klein). Therefore the community in which one resides will have an effect on their interaction patterns, and as a result may have an effect on their social resources. The last assumption which is important for this study is that actions should be understood on various levels (White \& Klein). This study focuses primarily on the personal and community levels. 
For families, the ecosystem consists of the family itself and its environmental interactions. Individuals are affected by multiple forces on multiple ecological levels. The levels are seen as nested within one another, meaning that the larger systems also contain the smaller systems (Bronfenbrenner, 1979). The smallest system, the microsystem, refers to interactions between an individual and the present immediate environment. Next is the mesosystem, which refers to interactions between the different microsystems to which an individual belongs. This could include interactions between home and work for parents or, for parents of children with chronic illnesses, interactions between the home, work, and healthcare environments. The exosystem refers to environments which do not directly contain the individual, but still influence the individual and/or their current environment. For parents, their child's school is usually a part of the exosystem, as they are not typically present in the school yet are affected by the requirements of the school and their child's feelings about the school. The macrosystem does not refer to any physical environment, but rather the cultural influences which affect environments. This can include, but are not limited to, laws, cultural norms, and religious beliefs. The chronosystem was added later (Bronfenbrenner, 1989) and refers to the element of time and how timing also affects how an individual responds to events.

Ecosystems contain niches, or regular patterns of activities (White \& Klein, 2008). These patterns dictate the tasks required to facilitate functioning and adapt in order to ensure needs are met. For example, many mother's fill child-rearing roles in their family by taking on tasks such as preparing the child's meals and providing 
emotional support. In this sense, many mothers are a part of the childcare niche. Parents of children with chronic illnesses may need to develop unique niches in order to accommodate the needs of their family. Every individual also has an adaptive range (White \& Klein, 2008). This means individuals have a range of abilities and resources to draw on, but options available are limited to this range. Parents of children with chronic illnesses will have an adaptive range for adjusting to their child's diagnosis and related needs.

Motivation sequence. The Thinking-Feeling-Acting (TFA) Model has been used in counseling both to support the counselor-client relationship and to better understand an individual's response in different situations (Mueller, Dupuy, \& Hutchins, 1994). However, TFA can also be looked at as a sequence which can explain human behaviors, responses, and outcomes. For example, when one thinks their effort has resulted in their success, they will be more likely to experience the feeling of pride in their work, which will affect their effort and expectation for success in the future (Graham, 1994). Bernard Weiner (2012) points out, in relation to his Attribution Theory of Motivation, that thinking guides feelings and feelings guide actions or behaviors. This provides a useful framework for seeing how community support might affect the experience of posttraumatic growth. Community support will likely affect how one thinks about the challenges of caring for a child with a chronic illness, these thoughts will affect how one feels about the challenges, which will in turn affect their behaviors and, perhaps, their PTG outcomes. 


\section{REFERENCES}

Barakat, L. P., Alderfer, M. A., \& Kazak, A. E. (2006). Posttraumatic growth in adolescent survivors of cancer and their mothers and fathers. Journal of Pediatric Psychology, 31(4), 413-419.

Barr, P. (2011). Posttraumatic growth in parents of infants hospitalized in a neonatal intensive care unit. Journal of Loss \& Trauma, 16(2), 117-134. doi: 10.1080/15325024.2010.519265

Benetato, B. B. (2011). Posttraumatic growth among Operation Enduring Freedom and Operation Iraqi Freedom amputees. Journal of Nursing Scholarship, 43(4), 412-420. doi: 10.1111/j.1547-5069.2011.01421.x

Branstetter, J. E., Domian, E. W., Williams, P. D., Graff, J. C., \& Piamjariyakul, U. (2008). Communication themes in families of children with chronic conditions. Issues in Comprehensive Pediatric Nursing, 31(4), 171-184.

Bronfenbrenner, U. (1979). The ecology of human development. Cambridge, MA: Harvard University Press.

Bronfenbrenner, U. (1989). Ecological systems theory. In R. Vasta (Ed.), Annals of child development (Vol. 6, pp.187-249). Greenwich, CT: JAI.

Calhoun, L.G., \& Tedeschi, R.G. (2006). The foundations of posttraumatic growth: An expanded framework. In L.G Calhoun, \& R.G. Tedeschi (Eds.), Handbook of posttraumatic growth (pp. 3-23). Mahwah, NJ: Lawrence Erlbaum Associates.

Connerty, T. J., \& Knott, V. (2013). Promoting positive change in the face of adversity: experiences of cancer and post-traumatic growth. European Journal of Cancer Care, 22(3), 334.

Coyne, I.T. (1997). Chronic Illness: The importance of support for families caring for a child with Cystic Fibrosis. Journal of Clinical Nursing, 6(2), 121-129.

Dekel, R., \& Nuttman-Shwartz, O. (2009). Posttraumatic stress and growth: the contribution of cognitive appraisal and sense of belonging to the country. Health \& Social Work, 34(2), 87-96. 
Engelkemeyer, S. M., \& Marwit, S. J. (2008). Posttraumatic growth in bereaved parents. Journal of Traumatic Stress, 21(3), 344-346. doi: 10.1002/jts.20338

Fauman, K. R., Pituch, K. J., Han, Y. Y., Niedner, M. F., Reske, J., \& LeVine, A. M. (2011). Predictors of depressive symptoms in parents of chronically ill children admitted to the pediatric intensive care unit. American Journal of Hospice and Palliative Care, 28(8), 556-563.

Gall, T. L., Charbonneau, C., \& Florack, P. (2011). The relationship between religious/spiritual factors and perceived growth following a diagnosis of breast cancer. Psychology \& Health, 26(3), 287-305. doi: 10.1080/08870440903411013

Gasparini, A. (2010). Community and territorial belonging. Comparative Sociology, 9(4), 433-462. doi: 10.1163/156913210X12555713197097

George, A., Vickers, M. H., Wilkes, L., \& Barton, B. (2006). Chronic grief: Experiences of working parents of children with chronic illness. Contemporary Nurse: A Journal for the Australian Nursing Profession, 23(2), 228-242. doi:

10.5172/conu.2006.23.2.228

Graham, S. (1994). Motivation in African-Americans. Review of Educational Research, 64(1), 55-117.

Herrero, J., \& Garcia, E. (2007). Measuring perceived community support: Factorial structure, longitudinal invariance, and predictive validity of the PCSQ (perceived community support questionnaire). Journal of Community Psychology, 35(2), 197-217.

Holtslander, L., Kornder, N., Letourneau, N., Turner, H., \& Paterson, B. (2012). Finding straight answers: Identifying the needs of parents and service providers for adolescents with type 1 diabetes to aid in the creation of an online support intervention. Journal of Clinical Nursing, 21(17/18), 2419-2428.

Ireys, H.T., Chernoff, R.C., DeVet, K.A., Kim, Y. (2001). Maternal outcomes of a randomized controlled trial of a community-based support program for families of children with chronic illnesses. Archives of Pediatric and Adolescent Medicine, 155(7), 771-777.

Itzhaky, H., \& Schwartz, C. (2000). Empowerment of parents of children with disabilities: The effect of community and personal variables. Journal of Family Social Work, 5(1), 21-36.

Johnson, H., Thompson, A., \& Downs, M. (2009). Non-Western interpreters' experiences of trauma: The protective role of culture following exposure to oppression. Ethnicity \& Health, 14(4), 407-418. 
Johnston, A.C., Worrell, J.L., Di Gangi, P.M., \& Wasko, M. (2013). Online health communities: An assessment of the influence of participation on patient empowerment outcomes. Information, Technology, \& People, 26(2), 213-235.

Kazak, A.E. (1989). Families of chronically ill children: A systems and socialecological model of adaptation and challenge. Journal of Consulting and Clinical Psychology, 57(1), 25-30.

Konrad, S. C. (2006). Posttraumatic growth in mothers of children with acquired disabilities. Journal of Loss \& Trauma, 11(1), 101-113. doi: $10.1080 / 15325020500358274$

Li, Y., Cao, F., Cao, D., Wang, Q., \& Cui, N. (2012). Predictors of posttraumatic growth among parents of children undergoing inpatient corrective surgery for congenital disease. Journal of Pediatric Surgery, 47(11), 2011. doi: 10.1016/j.jpedsurg.2012.07.005

Mueller, R.O., Dupuy, P.J., \& Hutchins, D.E. (1994). A review of the TFA counseling system: From theory construction to application. Journal of Counseling Development, 72(6), 563-577.

Papaikonomou, M. (2012). Childhood cancer: A parent's perspective on social support, with a case illustration. Journal of Child and Adolescent Mental Health, 19(1), $65-73$.

Pearce, M. J., Singer, J. L., \& Prigerson, H. G. (2006). Religious coping among caregivers of terminally ill cancer patients: main effects and psychosocial mediators. Journal of Health Psychology, 11(5), 743-759.

Pedersen, S. D., Parsons, H. G., \& Dewey, D. (2004b). Stress levels experienced by the parents of enterally fed children. Child: Care, Health \& Development, 30(5), 507513.

Phelps, K. W., McCammon, S. L., Wuensch, K. L., \& Golden, J. A. (2009). Enrichment, stress, and growth from parenting an individual with an autism spectrum disorder. Journal of Intellectual \& Developmental Disability, 34(2), 133-141. doi: $10.1080 / 13668250902845236$

Rosenberg, A. R., Baker, K. S., Syrjala, K. L., Back, A. L., \& Wolfe, J. (2013). Promoting resilience among parents and caregivers of children with cancer. Journal of Palliative Medicine, 16(6), 645-652. doi: 10.1089/jpm.2012.0494

Salter, E., \& Stallard, P. (2004). Posttraumatic growth in child survivors of a road traffic accident. Journal of Traumatic Stress, 17(4), 335-340. 
Scrignaro, M., Barni, S., \& Magrin, M. E. (2011). The combined contribution of social support and coping strategies in predicting post-traumatic growth: A longitudinal study on cancer patients. Psycho-Oncology, 20(8), 823-831. doi: 10.1002/pon.1782

Seidmahmoodi, J., Rahimi, C., \& Mohamadi, N. (2011). Resiliency and religious orientation: factors contributing to posttraumatic growth in Iranian subjects. Iranian Journal of Psychiatry, 6(4), 145-150.

Splevins, K., Cohen, K., Bowley, J., \& Joseph, S. (2010). Theories of posttraumatic growth: Cross-cultural perspectives. Journal of Loss and Trauma, 15(3), 259-277.

Strauss, A.\& Corbin, J. (1998). Basics of qualitative research: Techniques and procedures for developing grounded theory. London: Sage.

Taku, K., Tedeschi, R. G., Cann, A., \& Calhoun, L. G. (2009). The culture of disclosure: Effects of perceived reactions to disclosure on posttraumatic growth and distress. Journal of Social \& Clinical Psychology, 28(10), 1226-1243.

Taubman-Ben-Ari, O., Findler, L., \& Kuint, J. (2010). Personal growth in the wake of stress: The case of mothers of preterm twins. Journal of Psychology, 144(2), 185-204.

Tedeschi, R.G., \& Calhoun, L.G. (1996). The Posttraumatic Growth Inventory: Measuring the positive legacy of trauma. Journal of Traumatic Stress, 9(3), 455-471.

Tedeschi, R.G., Calhoun, L.G., \& Cann, A. (2007). Evaluating resource gain: Understanding and misunderstanding posttraumatic growth. Applied Psychology: An International Review, 56(3), 396-406.

Thurman, T.R., Jarabi, B., \& Rice, J. (2012). Caring for the caregiver: Evaluation of support groups for guardians of orphans and vulnerable children in Kenya. AIDS Care, 24(7), 811-819.

Wei, Y., Chu, H., Chen, C., Hsueh, Y., Chang, Y., Chang, L. \& Chou, K. (2012). Support groups for caregivers of intellectually disabled family members: Effects on physical-psychological health and social support. Journal of Clinical Nursing, 21(11/12), 1666-1677.

Weiner, B. (2012). An attribution theory of motivation. In P.A.M. Van Lange., A.W. Kruglanski \& E.T. Higgins (Eds.), Handbook of theories of social psychology (135-155), London: SAGE Publications.

Yonemoto, T., Kamibeppu, K., Ishii, T., Iwata, S., \& Tatezaki, S. (2012). Posttraumatic stress symptom (PTSS) and posttraumatic growth (PTG) in parents of childhood, 
adolescent and young adult patients with high-grade osteosarcoma. International Journal of Clinical Oncology, 17(3), 272-275 


\section{APPENDIX A}

\section{PARENT RECRUITMENT POST}

Dear Child Life Forum,

My name is Colleen Gannon and I am a graduate student at Illinois State University completing my Master's degree in Family and Consumer Sciences with an emphasis in Child Life. I am conducting research for my Master's thesis that explores concepts of posttraumatic growth (positive outcomes of stress) and community belonging as they relate to parents of children with chronic illness.

Parents are eligible to take the survey if they have a child who has been professionally diagnosed with a chronic illness. I need and would greatly appreciate your help with this endeavor, as the goals of my research has potential to better inform our understanding of the Child Life specialist's role in supporting parents that have had a traumatic experience.

The email text and link to the survey are both provided here as an attachment. Simply copy and send the letter with the survey link to the parent participants via email.

Their participation is voluntary and will not be connected to you other than dissemination of information about the opportunity to participate in the study. If you have any questions, please feel free to contact me directly at cgannon@ilstu.edu or contact my faculty supervisor, Dr. Bill Anderson at jander2@ilstu.edu.

My sincere thanks for your time and consideration,

Colleen Gannon

M.S. Candidate

Family and Consumer Science- emphasis in Child Life

Illinois State University 


\section{APPENDIX B \\ CHILD LIFE SPECIALIST RECRUITMENT POST}

Dear Child Life Forum,

My name is Colleen Gannon and I am a graduate student at Illinois State University completing my Master's degree in Family and Consumer Sciences with an emphasis in Child Life. I am conducting research for my Master's thesis that explores the creation of community in the hospital environment. This research will allow you to reflect on the available supports in your setting and the potential benefits that creating community could offer to parents that have undergone a traumatic experience.

You are eligible to take the survey if you are a Child Life Specialist who works with chronically ill children and their families. I would greatly appreciate, and need your help with this endeavor, as the goals of my research has potential to better inform our understanding of the Child Life specialist's role in supporting parents that have had a traumatic experience.

The questionnaire is administered through the online survey software Select Survey. The link to the survey is provided below. It should take no longer than 10 minutes to complete.

The information that you provide will not be linked to you in any way. Data will be used as aggregate data in a database. All records will be kept confidential.

If you have any questions, please feel free to contact me directly at cgannon@ilstu.edu or contact my faculty supervisor, Dr. Bill Anderson at jander2@ilstu.edu.

To access the survey please follow click on the link below or copy and paste it into your web browser.

My sincere thanks for your time and consideration,

Colleen Gannon

M.S. Candidate

Family and Consumer Science- emphasis in Child Life

Illinois State University 


\section{APPENDIX C}

\section{PARENT DEMOGRAPHIC INFORMATION SURVEY}

What is your relationship to the child with a chronic illness/disability?

I I am the mother of a child with an illness, injury, and/or disability.

I am the father of a child with an illness, injury, and/or disability.

Other, please specify:

What is your current relationship status?

$\square$ I am married

$\square \quad$ I am a single parent

Other, please specify:

What was your relationship status at the time of your child's diagnosis?

I was a single parent when my child was diagnosed and/or injured.

I was married when my child was diagnosed and/or injured.

$\square$ Other, please specify:

Check your highest level of education:

I have a high school diploma or equivalent.

I attended some college.
I am currently attending college.

I have a college degree. 
$\square \quad$ I have a master's degree. $\quad \square \quad$ I have a doctoral degree

What is your current household income per month before taxes: (Check one)

$\square \quad \$ 0-\quad \square \quad \$ 1000-2000$

500

$\square \quad \$ 2000-3000$

- $\$ 50$

$0-\quad \square \quad \$ 3000-4000$

$100 \square \quad \square \quad \$ 4000$ and over

0

Which identity do you most identify as:

$\square$ Asian

$\square$ African American

Hispanic

What is your current age?
$48-55$

$56-60$

$\square \quad 61+$

$\square \quad 41-47$

How many children do you have?
1
3
2
4
5
6 or more 
At what age was your child diagnosed and/or injured?

$\square \quad$ 0-11 months

$\square \quad 1-3$ years

4-6 years
7-11 years

12-14 years

15-18 years

How old is your child with the illness, disability, or injury currently?
$\square \quad$ 0-11 months
7-11 years
$\square \quad 1-3$ years
12-14 years
$\square \quad 4-6$ years
15-18 years

How long has it been is your child was diagnosed and/or injured?

What type of illness, injury, and/or disability does your child was your child diagnosed with? 
What is the approximate size of the community in which you are currently living?

Less than 600

$50,000-200,000$

$600-5,000$

$200,000+$

$5,000-15,000$

$15,000-50,000$ 


\section{APPENDIX D \\ POSTTRAUMATIC GROWTH INVENTORY ELECTRONIC COPY}

Indicate for each of the statements below the degree to which this change occurred in your life as a result of your crisis [or researcher inserts specific descriptor here], using the following scale.

Note to investigators - you will need to format the items so that participants have a way of responding to each one. The procedure we recommend is to place the numerical values of the scale after each item.

In addition, the Roman numeral codes for the factors should also be removed.

$0=I$ did not experience this change as a result of my crisis.

$1=I$ experienced this change to a very small degree as a result of my crisis.

$2=I$ experienced this change to a small degree as a result of my crisis.

$3=$ I experienced this change to a moderate degree as a result of my crisis.

$4=I$ experienced this change to a great degree as a result of my crisis.

$5=I$ experienced this change to a very great degree as a result of my crisis.

1. I changed my priorities about what is important in life. (V)

2. I have a greater appreciation for the value of my own life. (V)

3. I developed new interests. (II)

4. I have a greater feeling of self-reliance. (III)

5. I have a better understanding of spiritual matters. (IV)

6. I more clearly see that I can count on people in times of trouble. (I)

7. I established a new path for my life. (II)

8. I have a greater sense of closeness with others. (I)

9. I am more willing to express my emotions. (I)

10. I know better that I can handle difficulties. (III)

11. I am able to do better things with my life. (II)

12. I am better able to accept the way things work out. (III)

13. I can better appreciate each day. (V)

14. New opportunities are available which wouldn't have been otherwise. (II)

15. I have more compassion for others. (I)

16. I put more effort into my relationships. (I) 
17. I am more likely to try to change things which need changing. (II)

18. I have a stronger religious faith. (IV)

19. I discovered that I'm stronger than I thought I was. (III)

20. I learned a great deal about how wonderful people are. (I)

21. I better accept needing others. (I)

Note: Scale is scored by adding all responses. Factors are scored by adding responses to items on each factor. Items to which factors belong are not listed on form administered to participants.

\section{PTGI Factors}

Factor I: Relating to Others

Factor II: New Possibilities

Factor III: Personal Strength

Factor IV: Spiritual Change

Factor V: Appreciation of Life 


\section{APPENDIX E \\ PERCEIVED COMMUNITY SUPPORT QUESTIONNAIRE}

Items are ranked on a 5-point scale ranging from (1) Strongly Disagree to (5) Strongly Agree

*Note: Dimension Categories will not be included on participant surveys.

\begin{tabular}{|c|c|}
\hline 1. I identify with my community. & Dimension I: Community Integration \\
\hline $\begin{array}{l}\text { 2. My opinions are valued in my } \\
\text { community. }\end{array}$ & Dimension I: Community Integration \\
\hline $\begin{array}{l}\text { 3. Few people in my community } \\
\text { know who I am. }\end{array}$ & Dimension I: Community Integration \\
\hline $\begin{array}{l}\text { 4. I feel like my community is my } \\
\text { own. }\end{array}$ & Dimension I: Community Integration \\
\hline $\begin{array}{l}\text { 5. I collaborate in organizations } \\
\text { and associations in my } \\
\text { community. }\end{array}$ & Dimension II: Community Participation \\
\hline $\begin{array}{l}\text { 6. I take part in activities in my } \\
\text { community }\end{array}$ & Dimension II: Community Participation \\
\hline $\begin{array}{l}\text { 7. I take part in activities in my } \\
\text { community. }\end{array}$ & Dimension II: Community Participation \\
\hline $\begin{array}{l}\text { 8. I respond to calls for support in } \\
\text { my community. }\end{array}$ & Dimension II: Community Participation \\
\hline $\begin{array}{l}\text { 9. I don't take part in socio- } \\
\text { recreational activities in my } \\
\text { community. }\end{array}$ & Dimension II: Community Participation \\
\hline $\begin{array}{l}\text { 10. I could find people that would } \\
\text { help me feel better }\end{array}$ & Dimension III: Community Organizations \\
\hline
\end{tabular}




\begin{tabular}{|c|c|}
\hline $\begin{array}{c}\text { 11. I could find someone to listen to } \\
\text { me when I feel down. }\end{array}$ & Dimension III: Community Organizations \\
\hline $\begin{array}{c}\text { 12. I would find a source of } \\
\text { satisfaction for myself. }\end{array}$ & Dimension III: Community Organizations \\
\hline $\begin{array}{c}\text { 13. I would be able to cheer up and } \\
\text { get in a better mood. }\end{array}$ & Dimension III: Community Organizations \\
\hline $\begin{array}{c}\text { 14. I would relax and easily forget } \\
\text { my problems. }\end{array}$ & Dimension III: Community Organizations \\
\hline
\end{tabular}




\section{APPENDIX F \\ CHILD LIFE SPECIALIST SURVEY}

What is your current age?

\begin{tabular}{|c|c|}
\hline $21-25$ & $\square \quad 41-50$ \\
\hline $26-32$ & $\square \quad 51-60$ \\
\hline $33-40$ & $\square \quad 60+$ \\
\hline
\end{tabular}

How many years have you been a child life specialist?

$\begin{array}{ll}\square \quad 1-2 \quad & 6-10 . \\ \square \quad 3-5 \quad & 11-15 \\ & \square \quad 15+\end{array}$

How many years have you worked at the hospital where you are currently employed?

$\begin{array}{ll}1-2 & 11-15 \\ 3-5 & \\ 6-10 & \\ & \end{array}$

What is the approximate size of the hospital where you are currently employed?
99 or fewer beds
100-199 beds
200-299 beds
300-399 beds 
What areas of the hospital do you currently work?

Select the gender with which you most identify"

- Male

$\square \quad$ Female

Select your highest level of education

$\square \quad$ I have a high school diploma

$\square \quad$ I attended some college

$\square \quad$ I am currently attending college

The hospital I work in as in a(n):

Urban Community

Suburban Community $\square \quad$ I have a college degree

$\square \quad$ I have a master's degree

$\square \quad$ I have a doctoral degree 
Do you believe your hospital makes efforts to create community for parents with chronic illnesses within the hospital? If yes, please describe:

Have you witnessed parents of children with chronic illnesses who have experienced positive life changes as a result of the experience of parenting a child with a chronic illness? If yes, please describe changes you have seen without identifying any patient or parent:

If answered yes to the previous question: Do you believe hospital programming or efforts to create community within the hospital had an effect on the parent's experience of positive changes? If yes, please explain: 


\section{APPENDIX G \\ INFORMED CONSENT LETTER: PARENTS}

Dear Participant:

My name is Colleen Gannon; I am a graduate student under the direction of Dr. Bill Anderson in the Department of Family and Consumer Sciences at Illinois State University. I am conducting a research study to explore how some parents experience positive outcomes following a stressful event, in this instance, the diagnosis of their child with a chronic illness.

I am requesting your participation, which will involve completing two questionnaires regarding your family and growing through a traumatic event. These two questionnaires should take no longer 10-20 minutes each. You will also be asked to provide some basic demographic information.

Your participation in this study is voluntary. Although the foreseeable risks are minimal and no adverse events are anticipated, some individuals may experience minimal psychological discomfort in completing the paper inventories as their child's condition 
will certainly be most salient at this time. If you choose not to participate or to withdraw from the study at any time, there will be no penalty. The results of the research study may be published, but your name will never be used.

Although there may be no direct benefit to you, the possible benefit of your participation is improved efforts to support parents who have experienced this event.

If you have any questions concerning the research study, please call me at (319) 5049014 or Dr. Bill Anderson at (309) 438-3256.

Sincerely, Colleen Gannon

If you have any questions about your rights as a subject/participant in this research, or if you feel you have been placed at risk, you can contact the Research Ethics \& Compliance Office at Illinois State University at (309) 438-2529. 


\section{APPENDIX H \\ INFORMED CONSENT LETTER: CHILD LIFE SPECIALISTS}

Dear Participant:

My name is Colleen Gannon; I am a graduate student under the direction of Dr. Bill Anderson in the Department of Family and Consumer Sciences at Illinois State University. I am conducting a research study to explore how some parents experience positive outcomes following a stressful event.

I am requesting your participation, which will involve completing a short questionnaire regarding creating community within the hospital environment and observed positive changes in parents' after a traumatic event. This questionnaires should take no longer 1015 minutes each. You will also be asked to provide some basic demographic information.

No marked risks are anticipated as a result of participating in this research. However, some participants may experience discomfort when answering questions related to their working with families of children with chronic illnesses as they may be reminded of 
some of the stresses of working with these families. Your participation in this study is voluntary. If you choose not to participate or to withdraw from the study at any time, there will be no penalty. The results of the research study may be published, but your name will never be used. Although there may be no direct benefit to you, the possible benefit of your participation is improved efforts to support parents who have experienced a traumatic event.

If you have any questions concerning the research study, please call me at (319) 5049014 or Dr. Bill Anderson at (309) 438-3256.

Sincerely, Colleen Gannon 